\title{
Propofol attenuates responses of the auditory cortex to acoustic stimulation in a dose-dependent manner: a FMRI study
}

Citation for published version (APA):

Dueck, M. H., Petzke, F., Gerbershagen, H. J., Paul, M., Hesselmann, V., Girnus, R., Krug, B., Sorger, B., Goebel, R. W., Lehrke, R., Sturm, V., \& Boemer, U. (2005). Propofol attenuates responses of the auditory cortex to acoustic stimulation in a dose-dependent manner: a FMRI study. Acta Anaesthesiologica Scandinavica, 49(6), 784-791. https://doi.org/10.1111/j.1399-6576.2005.00703.x

Document status and date:

Published: 01/01/2005

DOI:

10.1111/j.1399-6576.2005.00703.x

Document Version:

Publisher's PDF, also known as Version of record

\section{Document license:}

Taverne

Please check the document version of this publication:

- A submitted manuscript is the version of the article upon submission and before peer-review. There can be important differences between the submitted version and the official published version of record.

People interested in the research are advised to contact the author for the final version of the publication, or visit the DOI to the publisher's website.

- The final author version and the galley proof are versions of the publication after peer review.

- The final published version features the final layout of the paper including the volume, issue and page numbers.

Link to publication

\footnotetext{
General rights rights.

- You may freely distribute the URL identifying the publication in the public portal. please follow below link for the End User Agreement:

www.umlib.nl/taverne-license

Take down policy

If you believe that this document breaches copyright please contact us at:

repository@maastrichtuniversity.nl

providing details and we will investigate your claim.
}

Copyright and moral rights for the publications made accessible in the public portal are retained by the authors and/or other copyright owners and it is a condition of accessing publications that users recognise and abide by the legal requirements associated with these

- Users may download and print one copy of any publication from the public portal for the purpose of private study or research.

- You may not further distribute the material or use it for any profit-making activity or commercial gain

If the publication is distributed under the terms of Article $25 \mathrm{fa}$ of the Dutch Copyright Act, indicated by the "Taverne" license above, 


\title{
Propofol attenuates responses of the auditory cortex to acoustic stimulation in a dose-dependent manner: A FMRI study
}

\author{
M. H. Dueck ${ }^{1}$, F. Petzke ${ }^{1}$, H. J. Gerbershagen ${ }^{1}$, M. Paul ${ }^{1}$, V. Herelmann ${ }^{2}$, R. Girnus, ${ }^{2}$ B. Krug ${ }^{2}$ B. Sorger ${ }^{3}$, R. Goebel ${ }^{3}$, \\ R. LEHRKE ${ }^{4}$, V. STURM ${ }^{4}$ and U. BOERNER ${ }^{1}$ \\ ${ }^{1}$ Department of Anaesthesiology and ${ }^{2}$ Department of Radiology, University of Cologne, Cologne, Germany, ${ }^{3}$ Department of Cognitive \\ Neuroscience, Faculty of Psychology, Universiteit Maastricht, Maastricht, the Netherlands, and ${ }^{4}$ Department of Stereotactic and Functional \\ Neurosurgery, University of Cologne, Cologne, Germany
}

\begin{abstract}
Background: Functional magnetic resonance imaging (fMRI) using blood-oxygen-level-dependent (BOLD) contrasts is a common method for studying sensory or cognitive brain functions. The aim of the present study was to assess the effect of the intravenous anaesthetic propofol on auditory-induced brain activation using BOLD contrast fMRI.

Methods: In eight neurosurgical patients, musical stimuli were presented binaurally in a block design. Imaging was performed under five conditions: no propofol (or wakefulness) and propofol plasma target concentrations of $0.5,1.0,1.5$, and $2.0 \mu \mathrm{g} \mathrm{ml}^{-1}$. Results: During wakefulness we found activations in the superior temporal gyrus (STG) corresponding to the primary and secondary auditory cortex as well as in regions of higher functions of auditory information processing. The BOLD response decreased with increasing concentrations of propofol but remained partially preserved in areas of basic auditory processing in the STG during propofol $2.0 \mu \mathrm{g} \mathrm{ml}^{-1}$.
\end{abstract}

Conclusions: Our results suggest a dose-dependent impairment of central processing of auditory information after propofol administration. These results are consistent with electrophysiological findings measuring neuronal activity directly, thus suggesting a dose-dependent impairment of central processing of auditory information after propofol administration. However, propofol did not totally blunt primary cortical responses to acoustic stimulation, indicating that patients may process auditory information under general anaesthesia.

Accepted for publication 23 December 2004

Key words: Auditory processing; functional imaging: fMRI; intravenous anaesthetics: propofol.

(C) Acta Anaesthesiologica Scandinavica 49 (2005)
$\mathrm{T}$ HERE is increasing knowledge about the actions of anaesthetic agents at the molecular level, whereas their effect on selected pathways of the central nervous system (CNS) remains an open issue. In general, auditory input is considered the last sensory modality to be blunted during anaesthesia (1). Functional magnetic resonance imaging (fMRI) is a non-invasive tool for studying the functioning of the human brain with the advantage of a much improved spatial resolution compared to the EEG-related method. It offers a promising approach for evaluating functional networks within the CNS, which has been demonstrated in previous studies of human central auditory processing (2).

Presented in part at the ASA Annual Meeting, San Francisco, California, October 2003.
The aim of the present study was to assess the activation of the auditory cortex at increasing targeted plasma concentrations of the intravenous anaesthetic propofol after acoustic stimulation using blood-oxygen-level-dependent (BOLD) contrast fMRI. Based on previous studies $(3,4)$, we hypothesized that propofol attenuates the auditoryinduced fMRI signal in a dose-dependent manner.

\section{Methods}

\section{Subjects}

The institutional review board of the University of Cologne approved the study. After obtaining written informed consent, we studied eight patients with ASA physical status I-III scheduled for stereotactically guided surgery of a brain tumour under 
general anaesthesia. All patients had to be nonmusicians and were examined neurologically prior to surgery. Exclusion criteria were a history of psychiatric disease (e.g. claustrophobia and depression), persisting neurological symptoms at the time of data acquisition (disturbances of auditory perception in particular), and left-handedness. A neuroradiologist reviewed preoperative MRI and/or CT-scans of all patients. Patients with shifts in midline or other tumour mass effects and localization of the tumour in brain areas associated with the auditory system were excluded.

\section{Experimental design and procedure}

Patients were kept fasting for at least $6 \mathrm{~h}$ prior to the investigation. During the experiment patients were placed supine on the gantry of the scanner and their heads were fixated to minimize involuntary head movements. Patients routinely received supplemental oxygen through a nasal canula at a rate of $31 \mathrm{~min}^{-1}$. Heart rate (HR), non-invasive mean arterial blood pressure (MAP), oxygen saturation $\left(\mathrm{SaO}_{2}\right)$, and endexpiratory $\mathrm{CO}_{2}\left(\mathrm{etCO}_{2}\right)$ were recorded in the middle of each functional run (Fig. 1) using a MR-compatible monitoring system.

Assessing the effect of propofol on the auditoryevoked BOLD signal requires an acoustic stimulus reliably inducing a stable and significant BOLD response in the auditory cortex. It has been shown that increasing stimulus complexity is associated with increased activation throughout the auditory cortical core and surrounding auditory regions (5). Therefore, a complex musical stimulus was presented binaurally. A digitally recorded sequence of the first $25 \mathrm{~s}$ of the Fourth Movement of L. vs. Beethoven's Ninth Symphony was delivered to the patients via air conduction through a semirigid silicone tube with an average intensity of $95 \mathrm{~dB}$. A Y-connector split the tube for binaural stimulation through a tightly fitting noise-shielding headphone which reduced the scanner noise to a maximum of $65 \mathrm{~dB}$ during the functional imaging sequences.

The experimental protocol comprised five experimental conditions (Fig. 1): wakefulness (or no propofol) and four levels of sedation defined by four propofol plasma target concentrations $\left(0.5 \mu \mathrm{g} \mathrm{ml}^{-1}, \quad 1.0 \mu \mathrm{g} \mathrm{ml}^{-1}, \quad 1.5 \mu \mathrm{g} \mathrm{ml}^{-1}\right.$, and $2.0 \mu \mathrm{g} \mathrm{ml}^{-1}$ ) administered by a target-controlledinfusion (TCI) system (Diprifusor ${ }^{\text {TM }}$, ALARIS, Medical Systems, Hampshire, UK). Each experiment started at wakefulness. Then, larger propofol target concentrations were delivered in ascending order. Plasma target levels were rapidly titrated by administration of bolus doses and maintained by a declining infusion rate. For each experimental condition, equilibration of the targeted plasma concentration and effect-site concentration as indicated by the TCI device had to be achieved before fMRI data acquisition was started.

During each experimental condition one functional data set (='functional run') was acquired (Fig. 1). During these functional runs the auditory
Acquisition of physiological data $\left(\mathrm{HR}, \mathrm{MAP}, \mathrm{SaO}_{2}, \mathrm{etCO}_{2}\right)$

ПDIMRI data acquisition (,functional run“)

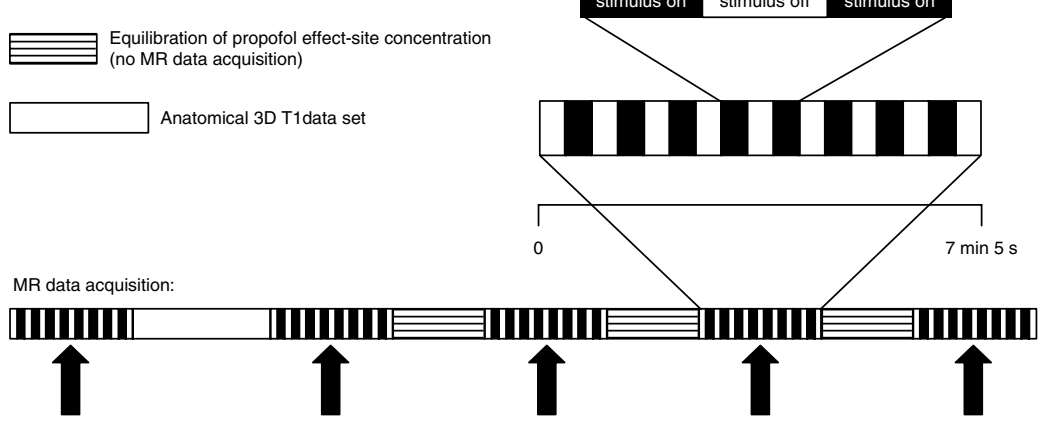

Experimental condition defined by targeted propofol effect site concentration $[\mu \mathrm{g} / \mathrm{ml}]$ :

\begin{tabular}{|c|c|c|c|c|c|c|c|c|}
\hline $0 \mu \mathrm{gl}^{-1}$ & $0.5 \mu \mathrm{gll}^{-1}$ & $0.5 \mu \mathrm{g} \mathrm{ml}^{-1}$ & $1.0 \mu \mathrm{g} \mathrm{ml}^{-1}$ & $1.0 \mathrm{~g} \mathrm{ml}^{-1}$ & & & & \\
\hline $\begin{array}{c}\text { condition 1 } \\
\text { wakefulness }\end{array}$ & equilibration & condition 2 & equilibration & condition 3 & equilibration & condition 4 & equilibration & condition 5 \\
\hline
\end{tabular}

Fig. 1. Scheme of the experimental protocol. The auditory stimulus was presented during five experimental conditions: wakefulness (or no propofol), and four levels of sedation defined by four propofol plasma target concentrations

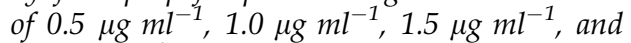
$2.0 \mu \mathrm{g} \mathrm{ml} l^{-1}$ using a target-controlled infusion system. Equilibration of targeted propofol plasma concentration and effect-site concentration was achieved prior to fMRI data acquisition. One functional run was acquired during each experimental condition. During these functional runs the auditory stimulus was presented in a block design composed of stimulation periods (stimulus on) alternating with resting periods defined by the absence of the experimental stimulus (stimulus off), with each period lasting 25 s. Physiological data (HR, MAP, SaO et $\mathrm{CO}_{2}$ ) were recorded in the middle of each functional run. 


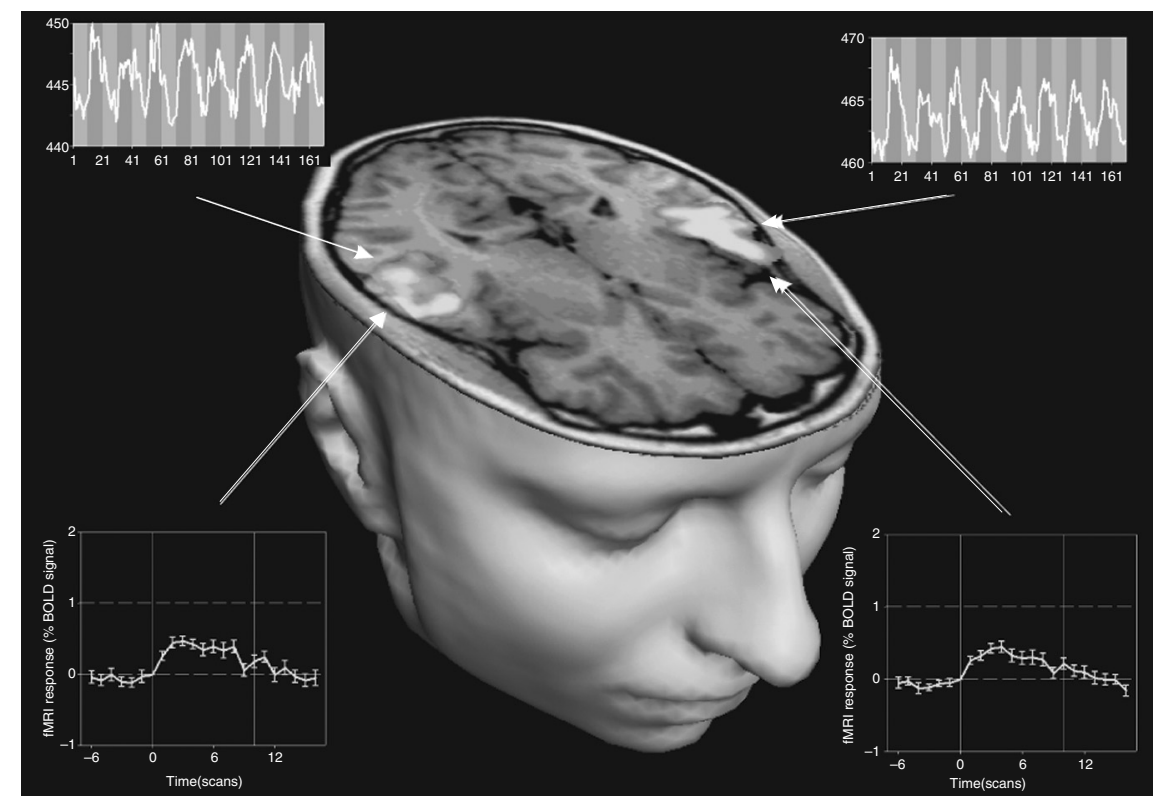

Fig. 2. Activation of the auditory cortex during acoustic stimulation. The transversal tomography shows the result of a group statistical parametric map of all subjects during wakefulness. The signal time courses (upper rectangles) depict the course of the BOLD signal of an individual subject while the lower rectangles demonstrate the mean BOLD signal plus standard deviation of the group analysis $(n=6)$. stimulus was presented in a block design composed of nine resting periods defined by the absence of the experimental stimulus (off-phase) interleaved with eight stimulation periods (on-phase). The total scan time for each functional run was 7 min $5 \mathrm{~s}$.

Throughout the study, an anaesthesiologist closely monitored the patients. MR-compatibleresuscitation material was readily available in the scanner room.

\section{Functional magnetic resonance imaging}

The MRI unit used was a commercial clinical whole body scanner with a magnetic field strength of 1.5 tesla (Gyroscan Intera, Powertrak 6000 Gradient Amplifier, Philips, Best, the Netherlands) provided with a standard quadrature head coil. Functional images were obtained using a single shot gradientecho planar imaging (EPI) sequence with the following parameters: repetition time $(\mathrm{TR})=2500 \mathrm{~ms}$, echo time $(\mathrm{TE})=50 \mathrm{~ms}$, flip angle $(\mathrm{FA})=90^{\circ}$, matrix size $=64 \times 64$, field of view $($ FOV $)=230 \times 230$, slice order $=$ descending, interleaved. Twenty-five contiguous horizontal slices with a slice thickness of $6 \mathrm{~mm}$ were orientated in parallel to the intercommissural line to cover the whole brain, including both the cortex and the cerebellum. For anatomical reference, a highquality whole brain 3D T1-weighted data set (scan parameters: $\mathrm{TR}=30 \mathrm{~ms}, \mathrm{TE}=4.6 \mathrm{~ms}, \mathrm{FA}=30^{\circ}$, number of slices $=200$, slice thickness $=1.0 \mathrm{~mm}$, no gap, total scan time $=7 \mathrm{~min} 54 \mathrm{~s}$ ) was acquired for every patient after the first functional run and before administration of propofol (Fig. 1).

\section{Statistical analysis}

Physiological data

Physiological variables ( $\mathrm{HR}, \mathrm{MAP}, \mathrm{SaO}_{2}$, and etCO were analyzed using ANOVA for repeated measures. A $P$-value $<0.05$ was considered significant. Results are presented as mean \pm SD unless otherwise stated. The Statistical Package for the Social Sciences (SPSS, release 11.0, SPSS Inc., IL) was used for analysis of the physiological data.

\section{Functional magnetic resonance imaging data}

Data preprocessing

Prior to further statistical analysis, each of the five functional runs per subject (corresponding to the five experimental conditions) was subjected to a series of preprocessing steps: temporal high-pass filtering, interscan motion detection and correction, smoothing of each functional volume by spatial convolution with a Gaussian kernel with a full width at a half maximum of $4 \mathrm{~mm}$, and Talairach-transformation of all anatomical and functional volumes to compare activated brain regions across subjects (6). Data sets with head movements $>3 \mathrm{~mm}$ or $3^{\circ}$ were excluded from further analysis. Only patients with a complete set of all five functional runs were included in the group analysis.

\section{Statistical analysis}

The statistical analysis was performed using a General Linear Model (GLM)-based statistical model of the expected changes of the fMRI signal. 
In our study the model included five predictors (or explanatory variables) corresponding to the five experimental conditions: wakefulness (predictor 1), propofol $0.5 \mu \mathrm{g} \mathrm{ml}^{-1}, 1.0 \mu \mathrm{g} \mathrm{ml}^{-1}, 1.5 \mu \mathrm{g} \mathrm{ml}^{-1}$, and $2.0 \mu \mathrm{g} \mathrm{ml}^{-1}$ (predictors 2-5). The fit of the model compared to the data is expressed as a statistical map, providing a statistical value for each individual voxel.

First, to analyze auditory processing in the unanaesthetized brain, a group-statistical parametric map of all subjects during wakefulness using $t$ statistics was calculated. A voxel was considered activated if the $t$-test comparing mean on-phase to off-phase BOLD signals resulted in $t$-values corresponding to a threshold of $P<0.05$ after a Bonferroni correction for multiple comparisons.

In a second step, one activated cluster in each auditory cortex (left and right) during wakefulness (no propofol) in the group map was defined as a region-of-interest (ROI) for a subsequent ROI analysis of experimental conditions $2-5$. This assured that the ROI was defined in an independent experiment. Accordingly, data during wakefulness were not included in the ROI analysis itself. ROI analysis was then performed referring to the mean of the fMRI signal of all voxels defining the ROI. Thus, the ROI analysis does not consider multiple voxels but analyzes only one single volume, resulting in a less conservative statistics, since correction for multiple comparisons is not necessary. Beta weights for both ROIs were then calculated for each of the propofol conditions to estimate the fit of the model to the data (in the least squares sense). High beta values indicate a 'strong' activation or good fit and low beta values indicate a 'weak or absent' activation or poor fit. Furthermore, the significance of the beta weights is estimated with a $t$ - and corresponding $P$-value.

As a third analysis step, individual statistical parametric maps of each patient during increasing propofol concentrations were examined and the last brain areas that demonstrated activation during increasing concentrations of propofol were determined for each individual.

The Brain Voyager 2000 software package (Version 4.7; Brain Innovation, Maastricht, the Netherlands) was used for all steps of the analysis of fMRI data. For anatomical reference the computed individual and group statistical maps were overlaid to anatomical scans. Activated clusters are reported using Talairach coordinates of the cluster's centre of spatial gravidity. Anatomical reference was checked using the Talairach Deamon Client (Version 1.1,
Research Imaging Center, University of Texas, San Antonio, TX). Furthermore, the minimal distances between brain tumour and ROI clusters of the auditory system for each patient was calculated using the respective Talairach coordinates.

\section{Results}

Demographic and physiological data

Two patients were excluded from data analysis due to massive head movement. Therefore, data sets of one female and five male patients with an average height of $177 \pm 13 \mathrm{~cm}$, weight of $79 \pm 24 \mathrm{~kg}$, and age of $44 \pm 15$ years were used for the final analysis. All patients were sedated during propofol target plasma concentrations of $2 \mu \mathrm{g} \mathrm{ml}^{-1}$, and promptly opened their eyes to verbal command. At this anaesthetic state all subjects spontaneously moved their heads and their upper and lower extremities to various degrees.

HR $(P=0.29)$ and MAP $(P=0.49)$ showed a slight but not significant decrease with increasing propofol plasma concentrations. Oxygen saturation was stable during the entire experiment. Three patients did not tolerate the nose canula necessary for measuring etCO $\mathrm{CtCO}_{2}$ values of the remaining three patients demonstrated a mean increase of $0.4 \mathrm{kPa}$ during propofol $2 \mu \mathrm{g} \mathrm{ml}^{-1}$ compared with wakefulness.

The mean minimal distance between brain tumour and the two ROIs within the auditory system was $49.6 \pm 21.1 \mathrm{~mm}$ (smallest distance $=29 \mathrm{~mm}$ ).

\section{Functional magnetic resonance imaging data}

In the group analysis the complex binaural musical stimulus evoked two large coherent clusters of activation in the bilateral auditory cortex during wakefulness, with the left cluster being greater than the right (Table 1). Both clusters included areas of superior temporal gyrus and adjoining regions, which are all involved in auditory processing (7), in particular music processing $(8,9)$. According to Brodmann's classification, these areas were further divided into area (BA) 41 or primary auditory cortex, BA 42 and 22 (secondary or associative auditory cortex), BA 13 (insula), BA 6 (premotor cortex), and BA 40 (somatosensory association cortex) (Table 1, Fig. 2). In the awake state, activation was additionally detected in the right prefrontal cortex (BA 45), an area related to higher functions of auditory music processing (10).

Region-of-interest analysis revealed a decline of the beta weights for each increase in propofol 


\section{H. Dueck et al.}

Table 1

Auditory-induced brain activation during wakefulness.

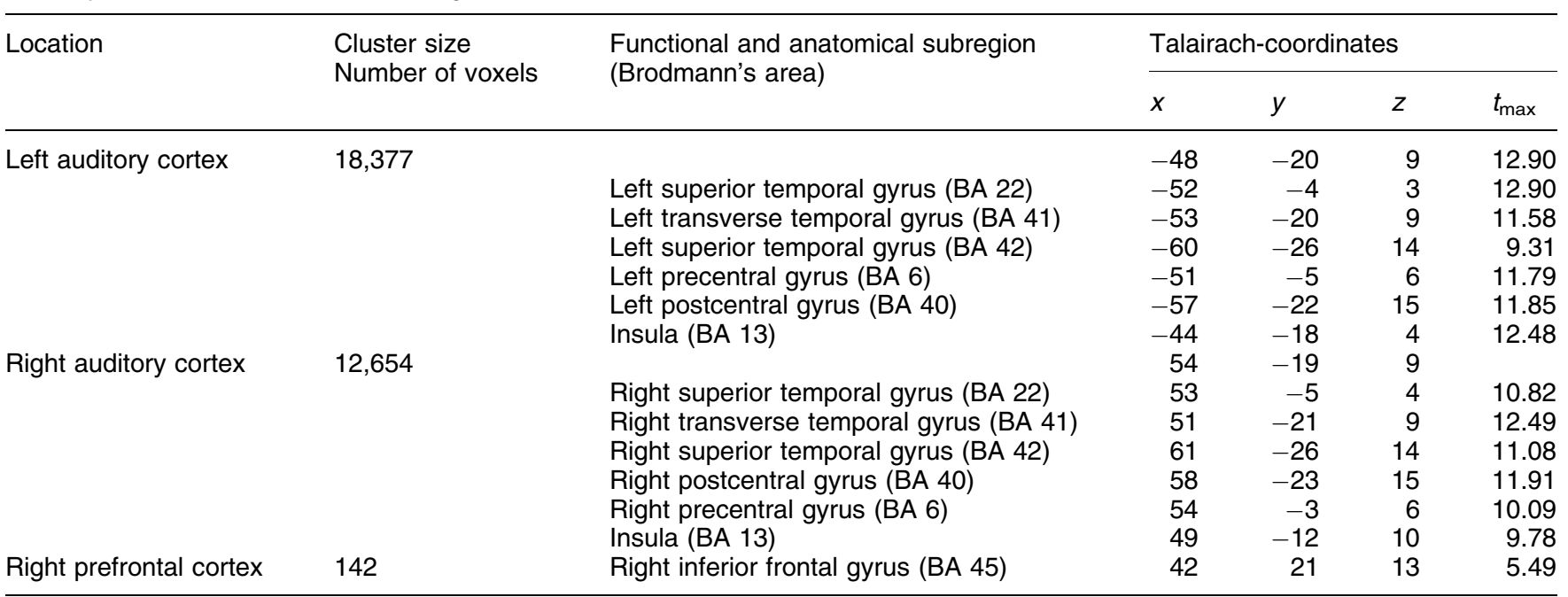

Acoustic stimulation during wakefulness resulted in two bilateral activation clusters of the auditory cortex plus an activated area in the right prefrontal cortex; a cluster represents an area of the statistical map that shows a significant difference of the on-phase BOLD (blood oxygen level-dependent) signal compared to the off-phase BOLD signal with a probability of $P<0.05$ (one-tailed, Bonferroni-corrected for multiple comparisons), which corresponds to a $t$-value $>4.90 ; x, y, z$-coordinates represent the centre of spatial gravity of a region in standardized Talairach space (6); functional and anatomical subregions are specified using the Talairach Deamon Client (Version 1.1, Research Imaging Center, University of Texas, San Antonio, TX); $t_{\text {max }}$ represents the local maximum of activation within an activated cluster; depicted data are results of a group analysis $(n=6)$.

plasma target concentration in the left as well as in the right auditory cortex (Table 2). Thus, administration of propofol seems to attenuate the acoustically induced BOLD signal dose-dependently. Furthermore, ROI analysis demonstrated the persistence of an auditory-evoked cortical activation even during propofol plasma target concentrations of $1.5 \mu \mathrm{g} \mathrm{ml}^{-1}$ (right auditory cortex) and $2.0 \mu \mathrm{g} \mathrm{ml}^{-1}$ (left auditory cortex) (Table 2). In the individual analysis, the primary (BA 41) and non-primary (BA 42, 22) auditory corteces were found to be the last activated brain regions during administration of increasing doses of propofol, whereas activation was abolished in all other areas that had been active during wakefulness (BA 6, 13, 40, and 45). Likewise, activation of the right prefrontal cortex during wakefulness was completely abolished during propofol plasma target concentrations of $0.5-2.0 \mu \mathrm{g} \mathrm{ml}^{-1}$.

Table 2

Auditory-induced brain activation during different propofol plasma target concentrations.

\begin{tabular}{llllr}
\hline Region-of-interest & Propofol plasma & Beta weight & $t$-value & $P$-value concentration \\
\hline Left auditory cortex & $0.5 \mu \mathrm{g} \mathrm{ml}^{-1}$ & 0.509 & 7.015 & $<0.00001$ \\
& $1.0 \mu \mathrm{g} \mathrm{ml}^{-1}$ & 0.333 & 4.595 & $<0.00001$ \\
& $1.5 \mu \mathrm{g} \mathrm{m}^{-1}$ & 0.310 & 3.314 & 0.00093 \\
Right auditory cortex & $2.0 \mu \mathrm{g} \mathrm{ml}^{-1}$ & 0.203 & 2.506 & 0.01227 \\
& $0.5 \mu \mathrm{g} \mathrm{ml}^{-1}$ & 0.481 & 5.626 & $<0.00001$ \\
& $1.0 \mu \mathrm{g} \mathrm{ml}^{-1}$ & 0.366 & 3.047 & $<00001$ \\
& $1.5 \mu \mathrm{g} \mathrm{ml}^{-1}$ & 0.356 & 1.876 & 0.00014 \\
\end{tabular}

Regions-of-interest (ROI) analysis of left and right auditory cortex; defined as those two clusters of activation in the auditory cortex that demonstrated auditory-induced activation during wakefulness. Note the decreasing beta weights, while corresponding propofol plasma concentrations increase. High beta values indicate a 'strong' activation, and low beta values indicate 'weak' activation. Corresponding $t$ and $P$-values describe the significance of the beta weights. Depicted data are results of a group analysis $(n=6)$. 


\section{Discussion}

The main findings of this study are: (1) Auditoryinduced activation during wakefulness was demonstrated in areas that are known to be involved in music processing; (2) propofol dose-dependently attenuated these acoustically induced BOLD responses in the auditory cortex, suggesting a dose-dependent impact of propofol on the central processing of auditory information; and (3) areas of higher functions of processing musical input were immediately lost when propofol was administered, whereas basic auditory information processing was preserved.

1. Listening to a complex musical stimulus during wakefulness induced activation in the superior temporal gyrus (STG) in regions adjacent to the STG and in the right inferior frontal gyrus, confirming results of previous studies (7-11). Zattore et al. found increases in cerebral blood flow in the superior temporal cortex during listening to melodies (7) and Griffiths et al. described the planum temporale [auditory association cortex (BA 42)] as engaged in the analysis of complex sounds (9). Furthermore, presenting complex auditory information as realized in our study activates a complex neural network, including sensory-motor functions (BA 6) and activation of frontal areas (BA 45 10).

2. During the awake state we found a larger area of auditory-induced activation in the left brain compared with the right brain. In contrast to traditional theories proposing a strong hemispheric specialization for music perception, it has been shown that musical information processing is based on highly individual cross-hemisphere networks (12). Therefore, the (pseudo-) lateralization of music processing observed in our study could be the result of individual aspects of musicality of the six patients examined and should not be generalized.

3. Our study supports previous findings that propofol affects central (cortical) auditory processing in a dose-dependent manner, since an increasing impairment of auditory-induced BOLD responses in the primary and non-primary auditory cortex during increasing propofol plasma target concentrations is demonstrated. The impact of anaesthesia on the auditory cortex, first reported by Erulkar et al. (13), has mostly been investigated by means of auditory evoked potentials (AEPs), which represent a direct measure of neuronal activation. Whereas brain stem auditory-evoked potentials, representing those early portions of the AEP generated in the auditory nerve and brainstem (14), remain largely unchanged during clinical anaesthesia (15), midlatency auditory evoked potentials (MLAEPs) are significantly affected by general anaesthetics $(1,16,17)$ and are now used for monitoring depth of anaesthesia (15). Midlatency auditory evoked potentials are widely accepted as generated from the medial geniculate and primary auditory cortex $(1,14)$. Previous studies reported that propofol dose-dependently attenuated MLAEP (4), thus suggesting a dose-related influence of propofol on cortical processing of auditory stimuli.

4. Another finding of this study is that auditory information is still processed in the STG at propofol plasma concentrations of $2 \mu \mathrm{g} \mathrm{ml}^{-1}$. 'Surviving' areas during administration of propofol were Heschl's gyrus and adjoining regions (BA 41, 42, 22). These parts of the auditory cortex are involved in primary, fundamental steps of central auditory information processing. In contrast, areas of higher functions of auditory information processing lost music-induced activation when increasing doses of propofol were administered. This finding of our study suggests a differential effect of propofol on central auditory information processing: complex analysis of acoustic input is impaired already at low propofol plasma concentrations, whereas basic auditory information is still being processed at high levels of sedation.

This is consistent with a clinical observation in the present study. All patients were sedated at the final plasma target concentration but promptly opened their eyes to verbal command. Since equilibration of targeted plasma concentration and effect-site concentration was achieved prior to each functional run, the effect-site concentration of propofol during the final functional run was approximately $2 \mu \mathrm{g} \mathrm{ml}^{-1}$, which is slightly less than the 'effect-site awakening propofol concentration' (18).

Our observation of a differential impairment of acoustic information processing is also consistent with previous studies (19-22). Ongoing auditory input processing potentially inducing implicit or explicit awareness during anaesthesia is a wellknown phenomenon (19-21). Recently, Heinke et al. reported that primary language processing in the temporal lobe was more resistant to propofol compared to areas of high-level processing in frontal brain regions (22).

The basic principle of the BOLD signal depends on the association of neuronal activation with an increase of regional cerebral blood flow and a proportional reduction in oxygen extraction resulting in a regional decrease of deoxyhemoglobin. This 
change of regional deoxyhemoglobin concentration can be detected by fMRI, thus representing an indirect measure of neuronal activation. Therefore, one might hypothesize that the depressing effect of propofol on acoustically evoked BOLD signals reported in our study may actually be due to different mechanisms: (1) a propofol-induced impairment of stimulus processing in the auditory cortex resulting in a reduction of neuronal activity or (2) a propofolrelated uncoupling of the oxidative metabolism and the cerebral haemodynamics reducing the BOLD signal independently of a change in brain activity.

Alkire et al. reported that propofol produced a global metabolic depression of the central nervous system (CNS), decreasing cortical metabolism to a greater extent than subcortical metabolism (23). Fiset et al. found propofol to preferentially decrease rCBF in the thalamus and the cingulated cortex (24), and Ogawa et al. described pronounced suppression in rCBF in the brain stem, thalamus, and parietal association cortex (25). However, it has been shown in animals (26) and in humans (27) that cerebral autoregulation is preserved after administration of propofol. The decrease in blood pressure observed in our subjects during propofol anaesthesia remained within the limits of cerebral autoregulation. An impact of propofol on CBF directly affecting the BOLD signal cannot be totally excluded. However, the authors suppose that the potential mechanism of an altered CBF can only induce slight effects, not explaining the observed change in the haemodynamic response. This suggests that the changes in acoustically evoked BOLD signal intensities during application of propofol found in our study are indeed caused by a change of neuronal activation.

The experiments of the current study were performed in patients scheduled for stereotactically guided surgery of a brain tumour. To minimize potentially confounding effects, patients with disturbances of auditory perception or tumour in the vicinity of the auditory system were excluded prior to the study. In fact, the actual distances between tumour and the auditory system were found to be at least $29 \mathrm{~mm}$ in each patient. Therefore, an impact of tumour-induced $\mathrm{CBF}$ changes on the BOLD response detected in our study seems unlikely.

BOLD contrast $\mathrm{fMRI}$ is a relatively new method to assess the effect of anaesthetic agents on brain functions. Our data confirm results of previous electrophysiological and neuroimaging studies demonstrating preserved auditory information processing during administration of propofol in the primary cortical processing areas. However, due to its high spatial resolution the fMRI method presents additional and more detailed information, showing that propofol has a differential impact on the cortical components of the auditory system. The fMRI method therefore goes beyond the scope of more traditional methods (i.e. electroencephalography, evoked potentials, magnetencephalography). It offers an approach to evaluate the effects of anaesthetic agents on functional and neuronal networks within the CNS. Clinically, our study offers a potential mechanism for awareness or recall phenomena reported by patients. Furthermore, fMRI is increasingly used as a diagnostic tool (28-30). Sometimes this requires appropriate sedation, particularly in children $(31,32)$. Our study shows that fMRI data analysis has to consider an impairment of auditoryinduced brain activation if propofol is used for sedation during $\mathrm{fMRI}$ of the auditory system.

In summary, our study confirms the hypothesis that propofol bilaterally attenuates the auditoryinduced BOLD signal of the auditory cortex in a dose-dependent manner. These results are consistent with electrophysiological findings directly measuring neuronal activity, indicating that our data reflect a propofol-induced dose-dependent impairment of central processing of auditory information. Despite its impact, propofol did not totally blunt primary cortical responses to acoustic stimulation, indicating that patients may process auditory information under general anaesthesia.

\section{References}

1. Thornton $C$, Sharpe RM. Evoked responses in anaesthesia. Br J Anaesth 1998; 81 (5): 771-81.

2. Binder JR, Frost JA, Hammeke TA, Cox RW, Rao SM, Prieto T. Human brain language areas identified by functional magnetic resonance imaging. J Neurosci 1997; 17 (1): 353-62.

3. Logothetis NK, Guggenberger H, Peled S, Pauls J. Functional imaging of the monkey brain. Nat Neurosci 1999; 2 (6): 555-62.

4. Thornton C, Konieczko KM, Knight AB et al. Effect of propofol on the auditory evoked response and oesophageal contractility. Br J Anaesth 1989; 63 (4): 411-7.

5. Patterson RD, Uppenkamp S, Johnsrude IS, Griffiths TD. The processing of temporal pitch and melody information in auditory cortex. Neuron 2002; 36 (4): 767-76.

6. Talairach G, Tournaux P. Co-Planar Stereotaxic Atlas of the Human Brain. New York: Thieme, 1988.

7. Zatorre RJ, Evans AC, Meyer E. Neural mechanisms underlying melodic perception and memory for pitch. J Neurosci 1994; 14 (4): 1908-19.

8. Liegeois-Chauvel C, Peretz I, Babai M, Laguitton V, Chauvel P. Contribution of different cortical areas in the temporal lobes to music processing. Brain 1998; 121: 1853-67.

9. Griffiths TD, Warren JD. The planum temporale as a computational hub. Trends Neurosci 2002; 25 (7): 348-53. 
10. Altenmuller EO. How many music centers are in the brain? Ann N Y Acad Sci 2001; 930: 273-80.

11. Zatorre RJ. Functional specialization of human auditory cortex for musical processing. Brain 1998; 121: 1817-8.

12. Schuppert M, Munte TF, Wieringa BM, Altenmuller E. Receptive amusia: evidence for cross-hemispheric neural networks underlying music processing strategies. Brain 2000; 123: 546-59.

13. Erulkar SD, Rose JE, Davies PW. Single unit activity in the auditory cortex of the cat. Bull Johns Hopkins Hosp 1956; 99: 55-86.

14. Celesia G, Brigell M. Auditory evoked potentials. In: Niedermeyer E, Lopes da Silva F, eds. Electroencephalography: Basic Principles, Clinical Application, and Related Fields. Baltimore, MD: Williams \& Wilkins, 1999: 995.

15. Drummond J. Monitoring depth of anesthesia: with emphasis on the application of the bispectral index and the middle latency auditory evoked response to the prevention of recall. Anesthesiology 2000; 93 (3): 876-82.

16. Pockett S. Anesthesia and the electrophysiology of auditory consciousness. Conscious Cogn 1999; 8 (1): 45-61.

17. Schwender D, Klasing S, Madler C, Poppel E, Peter K. Midlatency auditory evoked potentials and purposeful movements after thiopentone bolus injection. Anaesthesia 1994; 49 (2): 99-104.

18. Kazama T, Ikeda K, Morita K, Sanjo Y. Awakening propofol concentration with and without blood-effect site equilibration after short-term and long-term administration of propofol and fentanyl anesthesia. Anesthesiology 1998; 88 (4): 928-34.

19. Hilgenberg JC. Intraoperative awareness during high-dose fentanyl-oxygen anesthesia. Anesthesiology 1981; 54 (4): 341-3.

20. Schwender D, Kaiser A, Klasing S, Peter K, Poppel E. Midlatency auditory evoked potentials and explicit and implicit memory in patients undergoing cardiac surgery [see comments]. Anesthesiology 1994; 80 (3): 493-501.

21. Goldmann L. Information-processing under general anaesthesia: a review. J R Soc Med 1988; 81 (4): 224-7.

22. Heinke W, Fiebach CJ, Schwarzbauer C, Meyer M, Olthoff D, Alter K. Sequential effects of propofol on functional brain activation induced by auditory language processing: an event-related functional magnetic resonance imaging study. Br J Anaesth 2004; 92 (5): 641-50.
23. Alkire MT, Haier RJ, Barker SJ, Shah NK, Wu JC, Kao YJ. Cerebral metabolism during propofol anesthesia in humans studied with positron emission tomography. Anesthesiology 1995; 82 (2): 393-403.

24. Fiset P, Paus T, Daloze T et al. Brain mechanisms of propofolinduced loss of consciousness in humans: a positron emission tomographic study. J Neurosci 1999; 19 (13): 5506-13.

25. Ogawa K, Uema T, Motohashi N et al. Neural mechanism of propofol anesthesia in severe depression: a positron emission tomographic study. Anesthesiology 2003; 98 (5): 1101-11.

26. Werner C, Hoffman WE, Kochs E, Schulte am Esch J, Albrecht RF. The effects of propofol on cerebral and spinal cord blood flow in rats. Anesth Analg 1993; 76 (5): 971-5.

27. Engelhard K, Werner C, Mollenberg O, Kochs E. S (+)-ketamine/propofol maintain dynamic cerebrovascular autoregulation in humans. Can J Anaesth 2001; 48 (10): 1034-9.

28. Hunsche S, Sauner D, Treuer $\mathrm{H}$ et al. Optimized distortion correction of epi-based statistical parametrical maps for stereotactic neurosurgery. Magn Reson Imag 2004; 22 (2): 163-70.

29. Hesselmann V, Sorger B, Girnus R et al. Intraoperative functional MRI as a new approach to monitor deep brain stimulation in Parkinson's disease. Eur Radiol 2004; 14 (4): 686-90.

30. Thai-Van H, Fraysse B, Berry I et al. Functional magnetic resonance imaging may avoid misdiagnosis of cochleovestibular nerve aplasia in congenital deafness. Am J Otol 2000; 21 (5): 663-70.

31. Altman NR, Bernal B. Brain activation in sedated children: auditory and visual functional MR imaging. Radiology 2001; 221 (1): 56-63.

32. Souweidane MM, Kim KH, McDowall R et al. Brain mapping in sedated infants and young children with passivefunctional magnetic resonance imaging. Pediatr Neurosurg 1999; 30 (2): 86-92.

Address:

Michael H. Dueck, MD, DEAA

Department of Anaesthesiology

University of Cologne

Joseph-Stelzmann-Str. 9

D-50924 Cologne

Germany

e-mail: M.Dueck@uni-koeln.de 